\title{
THE EFFECT OF ANOXIA ON \\ THE VENTRICULAR FIBRILLATION \\ THRESHOLD IN THE RABBIT ISOLATED HEART
}

\author{
M.F. MURNAGHAN \\ Department of Physiology, University College, Dublin, Ireland
}

1 The ventricular fibrillation threshold (VFT) was measured in the isolated heart of the rabbit perfused via the aorta with McEwen's solution at $37^{\circ} \mathrm{C}$ by applying a single $10 \mathrm{~ms}$ pulse of current during the vulnerable period of late systole. The arrhythmia induced was either fibrillation or a rapid tachycardia.

2 Gassing the McEwen's solution with $5 \% \mathrm{CO}_{2}$ in $\mathrm{N}_{2}$ (anoxia) instead of with carbogen caused a negative inotropic and chronotropic effect and significantly lowered the VFT. Although anoxia releases noradrenaline from the heart the effect of anoxia on the VFT was not prevented by $\beta$-adrenoceptor blockade with propranolol or pindolol or by previous treatment with reserpine.

3 Perfusion with adenosine ( $5 \mu \mathrm{M})$ which is released from the heart muscle by anoxia, or with dipyridamole $(10 \mu \mathrm{M})$ which protects the adenosine from binding or destruction by the tissues, or with both combined failed to alter the VFT significantly. Furthermore neither adenosine nor dipyridamole significantly altered the effect of anoxia on the VFT.

4 Anoxia, adenosine and dipyridamole significantly increased the duration of the induced arrhythmia when compared with that of the controls.

5 Anoxia and adenosine significantly shortened the vulnerable time, i.e. the minimal time after the R-wave of the ECG at which the pulse had to be applied to induce the arrhythmia.

6 Perfusion with the McEwen's solution gassed with $5 \% \mathrm{CO}_{2}$ in air (hypoxia) significantly lowered the VFT but the effect was not as great as with anoxia. Isoprenaline when infused lowered the VFT but this effect was not potentiated by hypoxia.

7 The results indicate that (a) anoxia lowers the VFT in the perfused isolated heart of the rabbit and that this effect is not due to adenosine or noradrenaline released by the anoxia and

(b) hypoxia does not sensitize the heart to the arrhythmic effect of isoprenaline.

\section{Introduction}

There is a considerable body of undisputed evidence that a localized area of ischaemia with a resultant anoxia of that part of the heart muscle produced experimentally by occlusion of a coronary artery in animals (Harris, 1948; Chardack, Gage, Frederico, Cusick, Matsumoto \& Lanphier, 1964) or occurring spontaneously in man (Miller, 1939; Smith, 1939) gives rise to ventricular arrhythmias including fibrillation and also lowers the ventricular fibrillation threshold (VFT) of the infarcted area (Wiggers, Wégria \& Pinera, 1940; Shumway, Johnson \& Stish, 1957; Han, 1969). However, the experimental results obtained where there is a generalized hypoxia of the animal are contradictory. Coffman \& Gregg (1960) showed that asphyxia induced by tracheal occlusion produced ventricular fibrillation in one third of their dogs and Szekeres \& Papp (1967) found that ventilation with $5-10 \% \mathrm{O}_{2}$ lowered the
VFT in the cat. On the other hand Badeer \& Howarth (1959) showed that ventilation with $100 \% \mathrm{~N}_{2}$ failed to induce ventricular fibrillation in dogs and Turnbull, MacLean, Dobell \& Demers (1965) ventilating dogs with $5-10 \% \quad \mathrm{O}_{2}$ and Rogers, Spear, Moore, Horowitz \& Sonne (1973) using $10-16 \% \quad \mathrm{O}_{2}$ could detect no significant change produced on the VFT. These results appear to confirm the suggestion that a boundary or trigger zone between normal and hypoxic myocardium was important for initiating and maintaining cardiac arrhythmias (Harris, 1948). However, Badeer \& Howarth (1959) showed that when both coronary arteries were ligated so that apparently all the myocardium was rendered ischaemic, ventricular fibrillation occurred spontaneously in 9 out of 10 dogs.

In all of these studies on the whole animal the effect of $\mathrm{O}_{2}$ lack could have been influenced by 
extracardiac factors, e.g. release of catecholamines. In order to determine the direct effect of $\mathrm{O}_{2}$ lack on the heart it is therefore desirable to use an isolated heart preparation. Szekeres \& Papp (1967) found that when the heart-lung preparation of the cat was ventilated with $5 \% \mathrm{O}_{2}$ the VFT was raised. They ascribed this to lack of neural and hormonal influences.

The purpose of the present investigation was to study the effect of $\mathrm{O}_{2}$ lack on the isolated Ringer-perfused heart of the rabbit. Burn \& Huković (1960) had demonstrated that hypoxia predisposed to a persistent fibrillation but they did not measure the minimal current which was required to induce it. In this present study the effect of $\mathrm{O}_{2}$ lack on both the VFT and the duration of the arrhythmia has been measured. In addition; attempts have been made to elucidate the mechanism by which lack of $\mathrm{O}_{2}$ may predispose to cardiac arrhythmias.

\section{Methods}

Ventricular fibrillation or a rapid tachycardia was induced in rabbit hearts perfused via the aorta with McEwen's (1956) solution at $37^{\circ} \mathrm{C}$ by the method described previously (MacConaill \& Murnaghan, 1967). The fibrillation threshold was determined by measuring the minimal strength needed to produce arrhythmia of a $10 \mathrm{~ms}$ square-wave pulse of current applied after each 8th heart beat during the vulnerable period of late systole. It was achieved by testing at $5 \mathrm{~ms}$ steps during the latter half of the R-T interval. The minimal acceptable duration of the induced arrhythmia was set at $1 \mathrm{~s}$ because of difficulty in differentiating it from groups of 3 or 4 multiple extrasystoles.

The type of arhythmia induced, monitored on a large oscilloscope screen (Airmec), was recorded as fibrillation or tachycardia. The duration of the arrhythmia was listed as persistent $(>60 \mathrm{~s})$ or nonpersistent. If a normal rhythm had not returned after $60 \mathrm{~s}$, defibrillation was effected by manually infusing $0.3 \mathrm{M} \mathrm{KCl}$ (usually $0.5 \mathrm{ml}$ sufficed) into the aortic cannula. The term ventricular fibrillation threshold (VFT) was used to indicate the minimal current required to induce either fibrillation or tachycardia. In order to indicate the magnitude of change produced by the treatment on the VFT, despite the variation in magnitude of the latter among hearts, the VFT change ratio was calculated, i.e. VFT during treatment/VFT of the preceding control(s). If a drug was combined with anoxia or hypoxia then the former administered alone acted as control. The minimal time after the $R$ wave of the ECG at which the $10 \mathrm{~ms}$ pulse had to be applied to induce the arrhythmia was called the vulnerable time.

The perfusion apparatus consisted of three heat-exchange columns connected to a perspex block fitted with a tap so that the fluid from any one column could be selected. Each column was fed from a reservoir bottle; the control perfusion fluid was gassed with $5 \% \mathrm{CO}_{2}$ in $\mathrm{O}_{2}$. In order to expose the heart to anoxia the perfusion fluid was gassed with $5 \% \mathrm{CO}_{2}$ in $\mathrm{N}_{2}$; for hypoxia $5 \% \mathrm{CO}_{2}$ in compressed air was used. At the front of the block an opening, with tap, permitted the injection of $\mathrm{KCl}$ into the perfusion fluid just above the aortic cannula; at the back of the block was an opening, with tap, for removal of air bubbles from the cannula when required. Adenosine and dipyridamole when used separately were incorporated in the perfusion fluid; when combined the adenosine was dissolved in $160 \mathrm{~mm}$ sodium chloride and infused by a syringe pump at a constant rate into the aortic cannula via an opening on the side of the perspex block. Dipyridamole was dissolved in $0.1 \mathrm{M} \mathrm{HCl}$ and then diluted approximately 8000 times with McEwen's solution. Isoprenaline was dissolved in $160 \mathrm{mM}$ sodium chloride acidified with $\mathrm{HCl}$ to $\mathrm{pH} 5$ and infused with the syringe pump at a rate of $3.2 \mathrm{nmol} /$ minute. Reserpine $1 \mathrm{mg} / \mathrm{kg}$ was injected intraperitoneally 48 and $24 \mathrm{~h}$ before the rabbit was killed.

Perfusion with solutions deficient in $\mathrm{O}_{2}$ was rarely maintained for a period longer than $5 \mathrm{~min}$ in order to avoid undue depression of the heart. If the VFT had not been determined by the end of this anoxic or hypoxic period the heart was perfused with oxygenated McEwen's solution before testing again at higher current strengths with the $\mathrm{O}_{2}$-deficient solution. When dipyridamole, propranolol or pindolol were used they invariably were perfused for at least $10 \mathrm{~min}$ in oxygenated McEwen's solution before being perfused in an $\mathrm{O}_{2}$-deficient medium. Perfusion with adenosine and isoprenaline commenced simultaneously with the period of exposure to $\mathrm{O}_{2}$ lack.

The results are usually expressed by the arithmetic mean with its standard error. Significance of difference was determined by Student's $t$ test or the Chi-square test where appropriate.

Drugs used were: adenosine (B.D.H.), dipyridamole (Persantin, Boehringer Ingelheim Ltd.), propranolol (ICI), pindolol (Sandoz Products Ltd.), isoprenaline hydrochloride (Winthrop) and reserpine (Koch-Light Lab.).

\section{Results}

Throughout the course of perfusion of the heart with the McEwen's solution, the force of 
contraction decreased more than the coronary flow. In the 16 hearts in the first trial with anoxic McEwen's solution (i.e. gassed with $5 \% \mathrm{CO}_{2}$ in $\mathrm{N}_{2}$ ) at $132 \pm 13 \mathrm{~min}$ after the start of the perfusion, the preceding control systolic force was $12.6 \pm 3.2 \mathrm{~g}$ and the coronary flow $16.2 \pm 1.2 \mathrm{ml} /$ minute. On the last anoxic trial at $329 \pm 23 \mathrm{~min}$ they were $1.2 \pm 0.3 \mathrm{~g}$ and $9.6 \pm 1.0 \mathrm{ml} / \mathrm{min}$ respectively.

At the end of the period of perfusion with the anoxic McEwen's solution in 53 trials the heart rate had decreased by $84 \pm 7$ beats/min from the preceding control value of $185 \pm 6$, the force of contraction had decreased $60 \pm 3 \%$ and the coronary flow had increased. The magnitude of the negative inotropic effect was independent of the degree of contractility preceding the period of anoxia. However, the increase in coronary flow was clearly related to the control contractility of the heart. Early in the experiment when the latter was $10.6 \pm 0.5 \mathrm{~g}$ (20 trials) the increase in the coronary flow was $86 \pm 15.5 \%$; later when $3.5 \pm 0.6 \mathrm{~g}$ (19 trials) it was $45 \pm 9 \%$ and near the end of the experiment when $1.3 \pm 0.2 \mathrm{~g}$ (10 trials) it was only $12 \pm 4 \%$. Adenosine and dipyridamole when incorporated in the perfusion fluid increased the coronary flow.

In 6 trials the effect of anoxia on the Q-T interval was measured. Anoxia significantly $(P<0.001)$ shortened the interval by $44 \pm 6 \mathrm{~ms}$ from a control value of $131 \pm 4 \mathrm{~ms}$ despite a significant $(P<0.02)$ decrease in heart rate from $167 \pm 13$ to $117 \pm 11$ beats/minute. In 6 trials adenosine $(5 \mu \mathrm{M})$ alone and in 2 trials dipyridamole $(10 \mu \mathrm{M})$ alone had no significant effect on the Q-T interval. Dipyridamole when combined with adenosine (4 trials) significantly $(P<0.01)$ shortened the Q-T interval from $136.3 \pm 2.4$ to $118.8 \pm 3.2$ milliseconds.

\section{Ventricular fibrillation threshold}

In 32 out of 40 trials in 14 rabbit hearts the ventricular fibrillation threshold (VFT) was lowered during the period of anoxia (Table 1). The total duration of the period of applied anoxia was $4.5 \pm 0.44 \mathrm{~min}$; the time from its start until the arrhythmia was induced was $2.5 \pm 0.26$ minutes. The VFT varied between 2.5-63 $\mathrm{mA}$ in the controls and 1-16 mA during anoxia. In order to indicate the magnitude of change produced by anoxia on the VFT despite the variation in magnitude of the control values among hearts, the VFT change ratio was calculated, i.e. the VFT during anoxia/VFT of the preceding control(s). The mean \pm s.e. mean VFT change ratio for all 40 trials was $0.60 \pm 0.05$ (range $0.14-1.28$ ) which was significantly different from unity $(P<0.001)$. There was an indication in the results that if the anoxia was prolonged it was less likely to lower the VFT.

During anoxia of the heart muscle adenosine has been shown to be liberated and is believed by some workers (Berne, 1964; Rubio, Berne \& Katori, 1969) to account for the coronary vessel dilatation. The possibility that this mechanism could account for or influence the change in the VFT produced by anoxia had to be considered. However, when incorporated in the McEwen's solution adenosine $(5 \mu \mathrm{M})$ alone (20 trials), or $10 \mu \mathrm{M}$ dipyridamole alone (24 trials), which protects the former from destruction (Berne, 1966), or both combined ( 2 trials) failed to alter significantly the VFT change ratio $(0.82 \pm 0.09$,

Table 1 Effect of lack of oxygen and of drugs on induced ventricular fibrillation

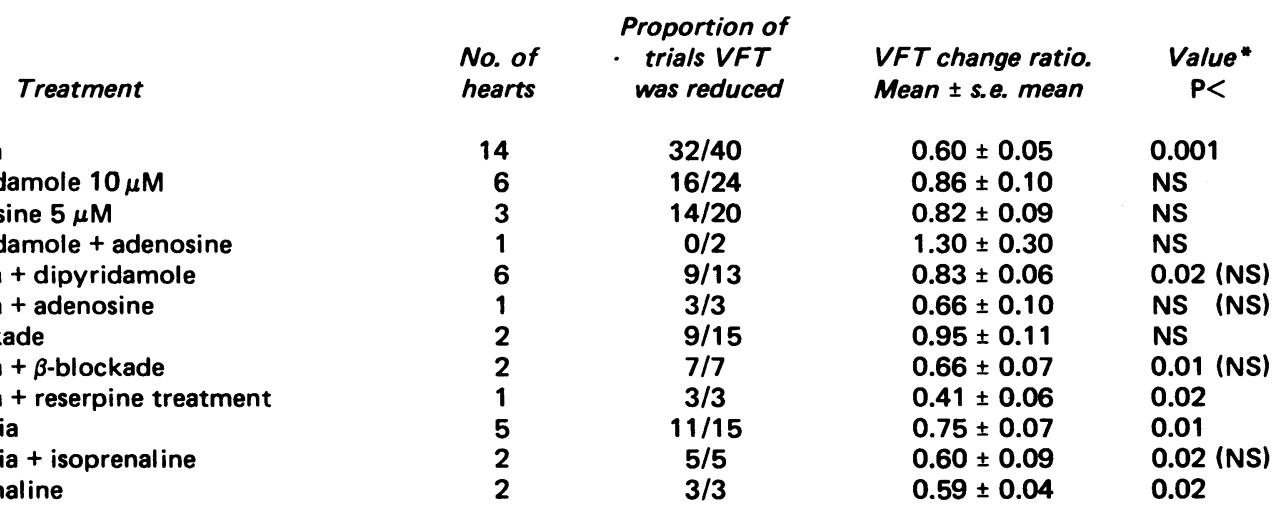

Anoxia

Dipyridamole $10 \mu \mathrm{M}$

Adenosine $5 \mu \mathrm{M}$

Dipyridamole + adenosine

Anoxia + dipyridamole

Anoxia + adenosine

$\beta$-blockade

Anoxia $+\beta$-blockade

Anoxia + reserpine treatment

Hypoxia

Hypoxia + isoprenaline

Isoprenaline

* Significance from unity and in parentheses comparison with $\mathrm{O}_{2}$ lack alone restricted to tests on the same hearts. 
$0.86 \pm 0.10$ and $1.30 \pm 0.30$ respectively). Furthermore the fall in the VFT produced by anoxia during perfusion with $10 \mu \mathrm{M}$ dipyridamole $(0.83 \pm 0.06)$ in 13 trials was not significantly different from that produced in 17 trials by anoxia alone $(0.82 \pm 0.06)$ on the same 6 rabbit hearts but each VFT change ratio was significantly different from unity $(P<0.02$ and 0.01 respectively). Finally adenosine $(5 \mu \mathrm{M})$ in 3 trials did not significantly alter the response to anoxia $(0.66 \pm 0.10)$ compared with 4 trials of anoxia alone on the same two hearts $(0.67 \pm 0.14)$. However, neither mean was significantly different from unity probably because of the small number of values in each case.

During anoxia noradrenaline is liberated from the rabbit isolated perfused heart (Wollenberger \& Shahab, 1965) and when infused into it has been shown to lower the VFT (Murnaghan, 1975). However, this mechanism does not appear to be responsible for the fall in the VFT during anoxia because when the $\beta$-adrenoceptors were blocked with propranolol $(2 \mu \mathrm{M})$ or pindolol in 7 trials the VFT was still significantly reduced by anoxia $(0.66 \pm 0.07 ; P<0.01)$. Additional evidence that the release of noradrenaline is not responsible for the fall in the VFT during anoxia is the fact that the fall was not prevented by previous treatment with reserpine (VFT change ratios of $0.44,0.50$ and 0.29 in three trials in one heart). The $\beta$-blockers alone in 15 trials did not significantly alter the VFT change ratio $(0.95 \pm 0.11)$ but have been shown to block the lowering effect of noradrenaline on the VFT (Murnaghan, 1975).

When the degree of $\mathrm{O}_{2}$ lack was made less extreme (hypoxia) by gassing the McEwen's solution with a mixture of $5 \% \mathrm{CO}_{2}$ in air instead of pure $\mathrm{N}_{2}$, the VFT was also reduced. The VFT change ratio of $0.75 \pm 0.07$ in 15 trials on 5 rabbit hearts was significantly different from unity $(P<0.01)$. Although the response with hypoxia was less marked than with anoxia they were not significantly different.

Since the introduction of isoprenaline inhala- tion for the treatment of bronchial asthma a number of fatalities have resulted. It has been conjectured that they may occur because the concomitant association of $\beta$-receptor cardiac stimulation and hypoxia induces ventricular fibrillation (McDevitt, Shanks \& Swanton, 1974).

Since both isoprenaline (Murnaghan, 1975) and hypoxia cause a moderate fall in the VFT, the possibility had to be considered that in combination they might act synergistically which could account for the fatalities in the treatment of bronchial asthma. Consequently isoprenaline ( $4 \mathrm{nmol} / \mathrm{min}$ ) was infused into two rabbit isolated hearts during perfusion with McEwen's solution gassed with $5 \% \mathrm{CO}_{2}$ in air. The fall of the VFT as indicated by its change ratio was not significantly greater during the combination of isoprenaline with hypoxia $(0.60 \pm 0.09$ for 5 trials $)$ than that with hypoxia alone $(0.81 \pm 0.11$ for 2 trials $)$. Furthermore, the effect of infusing isoprenaline alone $(0.59 \pm 0.04$ for 3 trials $)$ in the same two hearts was not significantly different from that when it was combined with hypoxia.

\section{Duration and type of arrhythmia}

Any procedure which converts a non-persistent to a persistent arrhythmia will predispose to a fatal outcome in the whole animal. Consequently the proportion of arrhythmias which were persistent in the perfused rabbit heart during the control and test periods have been compared. A similar comparison has been made in regard to whether the arrhythmia induced was a tachycardia or a fibrillation.

Anoxia significantly $(P<0.001)$ increased the incidence of a persistent arrhythmia (37 out of 40 ) compared with that of the corresponding controls $(126 / 271)$ in the same 14 rabbit hearts. Adenosine alone $(17 / 20$; controls $30 / 61)$ had a similar effect in 3 rabbit hearts $(P<0.02)$. Dipyridamole alone (19/24; controls $59 / 111)$ also had a similar effect in 6 rabbit hearts $(P<0.05)$. All other possible comparisons were insignificant. No treatment

Table 2 Vulnerable times, mean \pm s.e. mean ms, during control and test periods

$\begin{array}{lcccc} & \begin{array}{c}\text { No. of } \\ \text { hearts }\end{array} & \text { Control } & \text { Test } & \text { P< } \\ \text { Anoxia } & 12 & 78.0 \pm 4.2(196) & 54.6 \pm 4.2(23) & 0.05 \\ \text { Anoxia + dipyridamole } & 6 & 75.5 \pm 1.7(101) & 57.5 \pm 5.2(14) & 0.01 \\ \text { Adenosine } & 3 & 78.8 \pm 2.1(59) & 67.2 \pm 3.2(18) & 0.01 \\ \text { Anoxia + adenosine } & 1 & 87.9 \pm 6.4(14) & 53.3 \pm 13.3(3) & 0.01 \\ \beta \text {-Blockade } & 2 & 72.4 \pm 4.7(19) & 72.9 \pm 7.5(14) & \text { NS } \\ \text { Anoxia + } \beta \text {-blockade } & 2 & & 68.8 \pm 3.9(8) & \text { NS }\end{array}$

Number of values in parentheses. 
significantly altered from the control the type of arrhythmia ( $42 \%$ fibrillations) which could be induced.

\section{Vulnerable time}

Since anoxia shortens the duration of the ventricular action potential one would expect that the vulnerable period would also be shortened. Because of variations among hearts, comparisons of the vulnerable times were restricted to those carried out on the same hearts. The results in Table 2 show that the vulnerable time was significantly shortened by anoxia alone or when combined with dipyridamole or adenosine and also by adenosine alone despite the fact that the heart rate was slowed in all cases. Dipyridamole alone or when combined with adenosine did not significantly alter the vulnerable time. However, $\beta$ adrenoceptor blockade prevented anoxia from significantly shortening the vulnerable time.

\section{Discussion}

The results of this study clearly indicate that a complete lack of $\mathrm{O}_{2}$ (anoxia) in the perfusion fluid significantly lowers the ventricular fibrillation threshold (VFT) in the rabbit heart and increases the incidence of a persistent arrhythmia. Although a reduced amount of $\mathrm{O}_{2}$ (hypoxia) in the perfusion fluid significantly lowered the VFT, the increase in the incidence of a persistent arrhythmia was small. These results on the duration of the arrhythmia in the isolated rabbit heart are in general agreement with those of Burn \& Hukovic (1967) and suggest that a boundary or trigger zone between normal and anoxic myocardium which occurs with coronary occlusion (Harris, 1948) is not essential for sensitization of the ventricles to electrically-induced fibrillation. However, it would appear that this boundary zone may be of importance in order that ventricular fibrillation may occur spontaneously because the incidence of its occurrence is markedly reduced when the degree of anoxia of the infarcted area is reduced by the administration of hyperbaric oxygen (Smith \& Lawson, 1962; Chardack et al., 1964) and spontaneously arising ventricular fibrillation was not seen during $\mathrm{O}_{2}$ lack in the rabbit isolated perfused heart. Such a boundary zone between normal and altered myocardium not only occurs in cardiac infarction but also where cold, drugs etc., are applied to a localized area of the myocardium.

The most important factor for the initiation of ventricular fibrillation is an asymmetry in recovery of excitability. This occurs normally during the repolarization phase of the myocardial action potential and only when a stimulus is applied during this vulnerable period is it capable of inducing ventricular fibrillation. During anoxia of the myocardium the duration of the action potential is reduced (Trautwein, Gottstein \& Dudel, 1954). As the ventricles do not consist of a homogeneous population of fibres, asymmetry in excitability during late systole is likely to be exaggerated by anoxia as has been shown to occur with ischaemia (Han, 1964) and sympathetic activity (Han, de Jalon \& Moe, 1964). Furthermore, differences in the degree of perfusion of various parts of the heart will magnify the asymmetry. Such lack of homogeneity in recovery of excitability will predispose to re-entry rhythms arising spontaneously or induced by a degree of stimulation less than normally required during the vulnerable recovery period. Assymmetry in the degree of depression of conduction by anoxia will contribute towards the initiation and maintenance of such re-entry rhythms. However, if maintenance of the anoxia is prolonged an excessive decrease in the membrane potential will reduce the excitability and so the likelihood of initiating an arrhythmia.

Some workers have produced evidence which indicates that the release of adenosine is responsible for the coronary vasodilatation produced by anoxia of the heart muscle. This is partly based on the fact that the vasodilator action of adenosine is potentiated by dipyridamole (Afonso \& O'Brien, 1967) and lidoflazine (Afonso, O'Brien \& Crumpton, 1968) which prevent the destruction and binding by the tissues of the released adenosine (Bunag, Douglas, Imai \& Berne, 1964; Kolassa, Pfleger \& Rummel, 1970; Afonzo \& O'Brien, 1971). Three methods have been used to produce myocardial anoxia in the anaesthetized animal: coronary artery occlusion (ischaemia), asphyxia and systemic hypoxaemia. During coronary artery occlusion the adenosine content of the heart muscle is increased (Olsson, 1970), the adenosine is released into the coronary venous sinus (Rubio et al., 1969) and the reactive hyperaemia after removal of the occlusion is potentiated by dipyridamole (Parratt \& Wadsworth, 1972) and lidoflazine (Jageneau, Schaper \& van Gerven, 1969). During asphyxia the amount of adenosine released into the pericardial sac has been shown to be increased (Rubio \& Berne, 1969). However, the coronary vasodilating action of systemic hypoxaemia is not potentiated by dipyridamole (Parratt \& Wadsworth, 1972) or lidoflazine (Afonso, 1969). Apparently only in the the first two is there evidence that adenosine may play a role in the induced vasodilatation. In the isolated heart, however, anoxia induced by perfusion with Ringer solution gassed with $\mathrm{N}_{2}$ 
causes the release of adenosine and this effect is potentiated by dipyridamole (Berne, 1966). The effect of anoxia on ventricular irritability has been studied by noting the incidence of spontaneously arising ventricular fibrillation and by measuring the fall in the VFT in the anaesthetized animal. Coronary artery occlusion lowers the VFT in the infarcted area (Wiggers et al., 1940) and gives rise to spontaneous ventricular fibrillation in a high proportion of trials (Badeer \& Howarth, 1959). During asphyxia spontaneous ventricular fibrillation occurs in about one-third the number of trials (Coffman \& Gregg, 1960). On the other hand systemic hypoxaemia neither predisposes to spontaneous ventricular fibrillation (Badeer \& Howarth, 1959) nor does it lower the VFT (Rogers et al., 1973). As indicated by this study, lack of $\mathrm{O}_{2}$ induced by gassing the McEwen's solution with $5 \% \mathrm{CO}_{2}$ in $\mathrm{N}_{2}$ or air lowers the VFT in the rabbit isolated perfused heart. It would appear therefore that anoxia in this preparation resembles more closely in its effects coronary artery occlusion or induced asphyxia rather than the induction of systemic hypoxaemia in the whole animal.

It is of interest to note that only in those cases where there is evidence that adenosine is released, did anoxia also either lower the VFT and/or predispose to spontaneous ventricular fibrillation. However, adenosine per se apparently is neither responsible for the fall in the VFT nor does it prevent the fall induced by anoxia in the rabbit isolated perfused heart. That it appears to play no role in this regard is substantiated by the results with dipyridamole which either alone or when combined with adenosine did not cause a fall in the VFT nor did it prevent anoxia from doing so. However, adenosine may play a permissive role in the maintenance of an induced arrhythmia because it significantly shortened the vulnerable time. As adenosine did not significantly alter the duration of the Q-T interval, the shortened vulnerable time suggests that vulnerability to a ventricular arrhythmia occurred earlier during repolarization. In the whole animal dipyridamole by preventing destruction and tissue binding of the released adenosine and thereby increasing coronary flow will reduce the effect of myocardial anoxia due to coronary occlusion or asphyxia and so offer protection against a fatal arrhythmia; its adenosine-sparing action consequently may act indirectly via coronary perfusion of collateral vessels rather than directly on the ventricular irritability. Although dipyridamole when combined with adenosine shortened the Q-T interval it did not alter the vulnerable time and it prevented adenosine from doing so. Consequently it appears to delay vulnerability until a later stage in the repolarization process which may have an antifibrillatory effect.

The fact that coronary artery occlusion and asphyxia predispose to ventricular fibrillation and cause the release of adenosine, while hypoxaemia does not, suggests that the former are probably more injurious procedures and produce actual damage to the tissue, either localized or widespread. The release of adenosine consequently may be an indicator of the degree of damage to the tissue which would be the determining factor predisposing to ventricular irritability. The isolated perfused anoxic heart would also fall under this category. Furthermore, additional factors may play a significant role in the initiation of an arrhythmia in the whole animal, e.g. release of catecholamines, localized increased concentration of extracellular potassium, $\mathrm{pH}$ decrease etc. It is well established that asphyxia is a potent stimulus to the sympathetic system and cardiac infarction in the dog has been shown to release catecholamines from the adrenal medulla (Ceremuzynski, Staszewska-Barczak \& Herbaczynska-Cedro, 1969). The effect of the released catecholamines in the whole animal, however, are complex as Han et al. (1964) have shown that infused adrenaline first lowers and then raises the VFT in the dog. Although anoxia causes the release of noradrenaline in the rabbit isolated perfused heart (Wollenberger \& Shahab, 1965) and noradrenaline lowers the VFT (Murnaghan, 1975), the released noradrenaline cannot be responsible for the fall in the VFT induced by anoxia because the effect is not prevented by blockade of the $\beta$-adrenoceptors by propranolol or pindolol or by previous depletion of noradrenaline in the heart by reserpine.

McDevitt et al. (1974) have shown that the sudden death induced by low doses of isoprenaline in hypoxaemic dogs is associated with cardiac standstill and not ventricular fibrillation. Clearly hypoxaemia does not sensitize the dog's heart to arrhythmic doses of isoprenaline. The fact that hypoxia in the rabbit isolated heart does not potentiate the lowering effect of isoprenaline on the VFT confirms that this combination does not predispose to ventricular arrhythmias. These findings suggest that sudden death in asthmatic patients under treatment with pressurized aerosols could be due to concomitant hypoxaemia if the cause of death is due to cardiac standstill but probably not if it is due to ventricular fibrillation.

The author wishes to thank the Irish Heart Foundation for financial support for this work. The material for this paper was presented in a preliminary form at the Fifth International Congress on Pharmacology in San Francisco, July 1972. 
AFONSO, S. (1969). Coronary vasodilator responses to hypoxia and induced tachycardia before and after lidoflazine. Amer. J. Physiol., 216, 297-300.

AFONSO, S. \& O'BRIEN, G.S. (1967). Enhancement of coronary vasodilator action of adenosine triphosphate by dipyridamole. Circulation Res., 20, 403-408.

AFONSO, S. \& O'BRIEN, G.S. (1971). Mechanism of enhancement of adenosine action by dipyridamole and lidoflazine in dogs. Arch. int. Pharmacodyn, Ther., 194, 181-196.

AFONSO, S., O'BRIEN, G.S. \& CRUMPTON, C.W. (1968). Enhancement of coronary vasodilator action of ATP and adenosine after lidoflazine. Circulation Res., 22, 43-48.

BADEER, H. \& HOWARTH, S.M. (1959). Role of acute myocardial hypoxia and ischaemic-nonischaemic boundaries in ventricular fibrillation. Amer. Heart J., 58, 706-714.

BERNE, R.M. (1964). Regulation of coronary blood flow. Physiol. Rev., 44, 1-29.

BERNE, R.M. (1966). Agents modifying myocardial blood flow. In The Myocardial Cell, eds, Briller, S.A. \& Conn, H.L. Jr., pp. 355-374. Philadelphia: University of Philadelphia Press.

BUNAG, R.D., DOUGLAS, C.R., IMAI, S. \& BERNE, R.M. (1964). Influence of a pyrimidopyrimidine derivative on deamination of adenosine by blood. Circulation Res., 15, 83-88.

BURN, J.H. \& HUKOVIĆ, S. (1960). Anoxia and ventricular fibrillation: with a summary of evidence on the cause of fibrillation. Br. J. Pharmac. Chemother., 15, 67-70.

CEREMUZYSKI, L., STASZEWSKA-BARCZAK, J. \& HERBACZYNSKA-CEDRO, K. (1969). Cardiac rhythm disturbances and the release of catecholamines after acute coronary occlusion in dogs. Cardiovasc. Res., 3, 190-197.

CHARDACK, W.M., GAGE, A.A., FREDERICO, A.J., CUSICK, J.K., MATSUMOTO, P.J.H. \& LANPHIER, E.H. (1964). Reduction by hyperbaric oxygenation of the mortality from ventricular fibrillation following coronary artery ligation. Circulation Res., 15, 497-502.

COFFMAN, J.D. \& GREGG, D.E. (1960). Ventricular fibrillation during uniform myocardial anoxia due to asphyxia. Amer. J. Physiol., 198, 955-958.

HAN, J. (1964). Nonuniform recovery of excitability in ventricular muscle. Circulation Res., 14, 44-60.

HAN, J. (1969). Ventricular vulnerability during acute coronary occlusion. Amer. J. Cardiol., 24, 857-864.

HAN, J., de JALON, P.G. \& MOE, G.K. (1964). Adrenergic effects on ventricular vulnerability. Circulation Res., 14, 515-523.

HARRIS, A.S. (1948). Terminal electrocardiographic patterns in experimental anoxia, coronary occlusion and haemorrhagic shock. Amer. Heart J., 35, 895-909.

JAGENEAU, A.H.M., SCHAPER, W.K.A. \& van GERVEN, W. (1969). Enhancement of coronary reactive hyperaemia in unanaesthetized pigs by an adenosine-potentiator (Lidoflazine). NaunynSchmiedebergs Arch. Pharmak., 265, 16-23.
KOlASSA, K., PFleger, K. \& RUMMEL, W. (1970). Specificity of adenosine uptake in the heart and inhibition by dipyridamole. Eur. J. Pharmac., 9, 265-268.

MacCONAILL, M. \& MURNAGHAN, M.F. (1967). Effect of adrenaline on the ventricular fibrillation threshold in the isolated rabbit's heart. $B r . J$. Pharmac. Chemother., 31, 523-536.

McDEVITT, D.G., SHANKS, R.G. \& SWANTON, J.G. (1974). Further observations on the cardiotoxicity of isoprenaline during anoxia. $\mathrm{Br}$. J. Pharmac., 50,335-344.

McEWEN, L.M. (1956). The effect on the isolated rabbit heart of vagal stimulation and its modification by cocaine, hexamethonium and ouabain. J. Physiol., 131, 678-689.

MILLER, H. (1939). Ventricular fibrillation as mechanism of sudden death in patients with coronary occlusion. New Engl. J. Med., 221, 564-569.

MURNAGHAN, M.F. (1975). The effect of sympathomimetic amines on the ventricular fibrillation threshold in the rabbit isolated heart. Br. J. Pharmac., 53, 3-9.

OLSSON, R.A. (1970). Changes in content in purine nucleotides in canine myocardium during coronary occlusion. Circulation Res., 26, 301-306.

PARRATT, J.R. \& WADSWORTH, R.M. (1972). The effect of dipyridamole on coronary post-occlusion hyperaemia and on myocardial vasodilation induced by systemic hypoxia. Br. J. Pharmac., 46, 594-601.

ROGERS, R.M., SPEAR, J.F., MOORE, E.N., HOROWITZ, L.H. \& SONNE, J.E. (1973). Vulnerability of canine ventricle to fibrillation during hypoxia and respiratory acidosis. Chest, 63, 986-994.

RUBIO, R. \& BERNE, R.M. (1969). Release of adenosine by the normal myocardium in dogs and its relationship to the regulation of coronary resistance. Circulation Res., 25, 407-415.

RUBIO, R., BERNE, R.M. \& KATORI, M. (1969). Release of adenosine in reactive hyperaemia of the dog heart. Amer. J. Physiol., 216, 56-62.

SHUMWAY, N.E., JOHNSON, J.A. \& STISH, R.J. (1957). The study of ventricular fibrillation by threshold determinations. J. thorac. Surg., 34, 643-653.

SMITH, F.J. (1939). Ventricular fibrillation as cause of sudden death in coronary artery thrombosis. Amer. Heart J., 17, 735-741.

SMITH, G. \& LAWSON, D.A. (1962). The protective effect of inhalation of oxygen at two atmospheres absolute pressure in acute coronary artery occlusion. Surg. Gynec. Obstet., 114, 320-322.

SZEKERES, L. \& PAPP, G. (1967). Effect of arterial hypoxia on the susceptibility to arrhythmia of the heart. Acta physiol. hung., 32, 143-162.

TRAUTWEIN, W., GOTTSTEIN, U. \& DUDEL, J. (1954). Der Aktionsstrom der Myokardfaser im Sauerstoffmangel. Pflügers Arch. ges. Physiol., 260, 40-60.

TURNBULL, A.D., MacLEAN, L.D., DOBELL, A.R.C. \& DEMERS, R. (1965). The influence of hyperbaric 
oxygen and of hypoxia on the ventricular fibrillation threshold. J. Thorac. Cardiovasc. Surg., 50, 842-847. WIGGERS, C.J., WÉGRIA, R. \& PINERA, B. (1940). The effect of myocardial ischaemia on the fibrillation threshold-the mechanism of spontaneous ventricular fibrillation following coronary occlusion. Amer. J. Physiol., 131, 309-316.
WOllenberger, A. \& Shahab, L. (1965). Anoxiainduced release of noradrenaline from the isolated perfused heart. Nature, Lond., 207, 88-89.

(Received March 20, 1975.

Revised April 27, 1975.) 